\title{
CIDADE E SAUDE: A ORGANIZAÇAO DO TEMPO E DO ESPAÇO NO ORIENTE E NO OCIDENTE*
}

\author{
CITY AND HEALTH: ORGANISATION OF TIME AND SPACE \\ IN THE EAST AND IN THE WEST
}

Jean-Pierre Goubert ${ }^{1}$

Existe, em francês, um provérbio clássico: "O que se concebe claramente, enuncia-se claramente”. Desejaria, hoje, não o desmentir.

Meu propósito será dividido em três momentos: o primeiro será consagrado à evolução histórica dos conceitos de cidade e de saúde. O segundo momento estudará um caso de passagem à modernidade através do exemplo da vacinação antivariólica no século XIX na França e na Algéria. A terceira parte de minha conferência será exclusivamente consagrada a dois problemas de saúde pública. O primeiro concerne à vacinação antivariólica e sua difusão na cidade e a partir da cidade; a segunda compreende a questão da moradia e dos cuidados do corpo. Nestes dois casos, tomarei como objeto identificar e comparar as politicas executadas e seus resultados com respeito à especificidade das modalidades de organização do tempo e do espaço, principalmente entre o fim do século XVIII e a primeira metade do século XX.

\section{UMA DEFINIÇÃO DOS CONCEITOS DE CIDADE E DE SAÚDE}

\section{A Cidade}

Retomemos o inicio de nosso propósito. A cidade, segundo a tradição mediterrânea. de base greco-romano e após judaica-cristã, define-se simbolicamente e juridicamente, em primeiro lugar, como um espaço dotado de uma identidade separada; ela comporta uma fronteira e apresenta-se como um espaço organizado, esta organização servindo como justificativa para a separação. Qualquer que seja o período histórico considerado, a gestão deste espaço organizado é detida por uma pessoa ou por um grupo de pessoas em virtude de uma autoridade superior (soberano, Deus, Estado), de quem eles são os representantes diretos ou indiretos.

Seja em solo cristão ou islâmico, a autoridade civil, quando ela é distinta da autoridade religiosa, apoia-se sempre, especialmente na cidade, sobre uma religião revelada e sobre personagens que a encarnam, seja um clérigo, sábios ou chefes de reza.

Não somente o espaço da cidade é organizado segundo esquemas variáveis e distintos entre o islão e o Cristianismo através de ruas, ruelas, praças, bairros especialmente aforados por certas ocupações e/ou por certas etnias, como também o tempo da cidade é ritmado, ordenado, tornado manifesto pela voz dos sinos ou pelos apelos do "muezzin" ou, mais ainda, pela presença alta do campanário ou do minarete.

Esta concentração de seres humanos, que é a cidade, é explicada, igualmente bem, pelas correntes de trocas das quais ela constitui um elo. A aritmética típica da cultura dos comerciantes aí é colocada ao lado das especulações dos matemáticos e de outras das Universidades, sobretudo no fim da Idade Média Cristã na Europa Ocidental e, de modo muito brilhante, especialmente na Matemática, na Astronomia e na Medicina, no Oriente Árabe-Muçulmano.

* Este texto foi preparado para uma conferência preferida na Faculdade de Saúde Pública da Universidade de São Paulo. a convite do CDH - Centro de Estudos do Crescimento e do Desenvolvimento do Ser Humano.

1 Professor da École des I lautos Études en Sciences Sociales. em Paris, especializado em I história Social e História da Saúde. End.: 54 Boulevard Raispail, 75006, Paris France. Tradu,cão: Elaine Pedreira Rabinovich. 


\section{A preocupação com a saúde}

Porque ela reúne os homens e os faz coabitar, a cidade é o lugar obrigatório de passagem, o que preconiza o dever de caridade para com os pobres, os desprovidos e os abandonados; porque ela é o lugar onde se desenvolvem os saberes e onde eles se institucionalizam e se diversificam, a cidade se preocupa com a saúde de seus cidadãos (cités - civismos) e isto por motivos variados, desde medidas policiais até cuidados por caridade e médicos.

Seja no tempo da peste em Atenas, cinco séculos a. C., ou na época da última epidemia na França em Marseille em 1720, as autoridades da cidade tentam separar o são do mal-são (enfermo), enterrar os empestados e desinfetar suas casas. E, nisto, elas seguem? na França, o modelo sanitário italiano da Idade Média, ele mesmo derivado de seu equivalente no Império árabe a partir dos séculos IX e X do calendário cristão, estando ambos sistemas fundamentados sobre atitudes preventivas e práticas de depuramento.

Em parte, pois, ao menos os cuidados com o corpo parecem prover da gestão das cidades. E, também, uma das condições de seu desenvolvimento. Tal é, por natureza, a imbricação das relações entre cidade e saúde.

Trata-se, no momento, contudo, de marcar as modalidades de sua evolução no curso do tempo. Em uma grande parte, a cultura em que é forjada a medicina de cada época propõe visões especificas do mundo e do corpo. Isto permitiu, segundo critérios distintos e às vezes opostos, separar inicialmente o puro do impuro, após o são do malsão, segundo uma visão cada vez mais laicizada e, finalmente. científica. Concomitantemente se afirma, pouco a pouco, uma conquista "relativista e individualista" da saúde, pelo menos no Ocidente e, principalmente, no meio urbano após o começo do século XIX.

No Oriente, em Maghreb e no Machrete, a história da saúde permanece, em sua maior parte, a ser feita e a ser escrita, mesmo que se saiba que a construção de hospitais foi bem estabelecida no século $\mathrm{X}$ e que o ensino prático da medicina que aí predomina rompeu com a tradição da Antigüidade. Como o precisa o aforismo 377 de Razi, um médico persa do século X: "A conservação de uma boa saúde se adquire por meio de um diagnóstico, de uma causa, de uma classificação; de um sinal, de um tratamento, de uma preparação, de um prognóstico, de uma supervisão".

Em outros termos, a arte médica resulta de uma filosofia da prática que, em si mesma, ins- creve-se em uma perspectiva de progresso. Em medicina, segundo Razi, mas também segundo Lacépède em História Natural (século XIX), o tempo representa o papel de uma instância formadora, porque a medicina se encontra colocada em perpétua referência aos fatos, às observações, aos objetos acumulados, c não mais em relação a regras intangiveis representadas pela tradição hipocrática e galênica.

Tal não parece ser o caso da saúde. ao menos segundo Emmanuel Kant, na terceira sessão do Conflito das Fuculdades (1798): "Podemos nos sentir bem de saúde (bien portant), isto é, julgar segundo um sentimento de bem-estar vital, mas não podemos jamais saber se estamos bem de saúde. A ausência do sentimento (de estar doente) não permite ao homem expressar que ele está bem a não ser dizendo que ele está bem na aparência”. Se avançarmos o enunciado de Kant, chegaremos então à afirmação segundo a qual a saúde é um objeto fora do campo do saber. Não haveria ciência(s) da saúde; a saúde seria um conceito vulgar e não científco, vulgar não significando trivial, mas ao alcance de todos. Homens do saber ou pessoas do povo, citadinos ou camponeses, ocidentais ou orientais?

Será que isto quer dizer que a questão filosófica está em contradição com o conceito vulgar? A resposta é negativa se nos referirmos a uma reflexão do filósofo francês René Dcscartes. Em uma carta de 1643, ele escreve: "Embora a saúde seja o maior de todos os bens no que concerne ao corpo, é contudo aquele ao qual nós dedicamos menos reflexão e que nós degustamos menos. $\mathrm{O}$ conhecimento da verdade é como a saúde da alma: assim que o possuímos, não se pensa mais nele”.

E Georges Canguilhen se pergunta: "Como e que nunca se pensou em reverter esta assimilação, que não nos tenhamos jamais perguntado se a saúde não seria a verdade do corpo?”2

Falta precisar o sentido da palavra verdade, isto é, concebê-lo no sentido latino de verás real ou regular/correto; dito de outro modo, em situacão de proximidade com relação a sanus (são) que possui os dois mesmos sentidos que o grego: intato ou bem conservado, e infalivel ou certo ${ }^{3}$.

Como não há saúde de um mecanismo, por exemplo, de um relógio, a saúde não pode ser assimilada a um efeito necessário de relações de tipo mecânico. Existe, assim, uma saúde livre, não condicionada. não contabilizada, não medida. Nesta medida ela não é um objeto para o higienista, não podendo ser aplicada para reger uma população, isto é, não a indivíduos mas a uma coletividade.

2 C. Canguillcen. La santé. Concept vulgaire et question philosophique. Sables éd., Toulouse, 1990, p. 15.

3 Dondc a cxpressao são c salvo. em francês, inglês e português. 
É precisamente no começo do século XVIII que o significado de verdade do conceito de saúde foi ocultado em proveito do de faticidade. Além disto, a saúde se toma o objeto de uma contabilidade, de um projeto político, de um espaço e de um tempo onde se exerce o controle administrativo da saude, primeiro na cidade, no século XVI, depois em todo o território dos Estados Nações mais poderosos, no século XIX.

Seguindo-se a análise proposta por Georges Canguilhen, podc-se apreender mais em profundidade a orientação seguida pelos Estados da Europa Ocidental do século XVIII ao século XX no que concerne à sua política sanitária tanto nas cidades da metrópole quanto nas dos Impérios coloniais.

A diferenciação com que este filósofo trabalha entre a saúde como expressão do corpo dado e do corpo produzido é, a este respeito, esclarecedora. A saúde do corpo dado é provada pelo fato que a verdade é possível na medida em que o corpo é um genótipo, efeito tanto necessário quanto singular dos componentes de um patrimônio genético. Ein oposição, a saúde do corpo produzido envia a uma segurança de risco, isto é, vivida, no duplo sentido de segurança contra o risco e de audácia para correr o risco. Na perspectiva onde o corpo é um produto, onde suas atividades são ligadas a um ambiente, a um modo de vida, a um tipo de trabalho ou de esporte, este condicionamento múltiplo contribui para moldar seu fenótipo.

É aqui, precisamente, que uma disciplina médica muito antiga e remodelada no século XIX encontra seu campo de aplicação e sua legitimação; falo da Higiene, mas também do conjunto de disciplinas que se inscrevem na mesma perspectiva modificadora, a da política, da ecologia, da medicina preventiva - e depois preditiva - da medicina do trabalho, sem esquecer a psiquiatria.

\section{SAÚDE, CIDADES E CULTURAS: A OCIDENTALIZAÇÃO EM MOVIMENTO}

\section{Da heterpnomia à autonomia}

Até o século XVII, no Ocidente, a questão fundamental não era "quem é o homem, seu corpo, sua saúde?”, questão que se nos tornou familiar como consequência de uma educação humanista.

A filosofia da antigüidade clássica, depois a filosofia medieval cristã, repousam sobre um pensamento diferente, senão inverso. Ela é heterônima. Em outros termos, e para expressar de modo esquemático, a norma moral é exterior ao homem. Ela é referida a outra coisa que não ele próprio, isto é, ao conhecimento de um universo harmonioso e hierarquizado, o cosmos, que engloba o homem.

Através de sua razão que lhe permite conhecer o cosmos e através de sua ação política que permite de o reproduzir, o homen culto da Antigüidade, citadino e cidadão ao mesmo tempo, é chamado a construir um microcosmo, a cidade política (polis) na qual ele deve viver segundo a finalidade última do universo que é o Bem. Esta ética do Bem supõe um acordo possível entre duas imagens do universo, macrocosmo e microcosmo, um equilíbrio entre seus elementos e seus humores que funda uma ordem harmoniosa, isto é um estado de saúde e de bem-estar, enquanto que todo desequilíbrio implica em desordem dito de outro modo, em problema, em afetaçãc ou doença, que sacerdotes e sacerdotisas dá Asclépios, mas também médicins savants e filósofos são aptos a sanar.

O pensamento cristão, que foi longamente um objeto de escândalo para a filosofia e para a sensibilidade antigas, inscreve-se no mesmo quadro de pensamento heterônimo. Contudo, uma diferença essencial apareceu. Se o ser humano continua a ser referido a outra coisa que ele mesmo, ele não o é mais à natureza mas a Deus, e a um Deus que é uma pessoa unindo duas naturezas, uma divina, outra humana (dogma da encarnação) e reunindo três pessoas (dogma da Trindade). A inovação é de porte: Deus é pessoal e o homem, criado à imagem de Deus, é ele também uma pessoa.

Esta perspectiva cristã, preparada pela reflexão judaica, introduz no Ocidente a idéia de homem no sentido atual de sujeito único, singular, livre, consciente e responsável. Desde então o tempo não é mais, como nos pregos, "uma certa imitação móvel da eternidade" (Platão, Timeu, 37d-38), cíclica e repetitiva. Ele dá características de irreversabilidade e de unicidade à história singular de uma vida, e ele engendra projetos de liberdade, de responsabilidade, que pertencem ao sujeito quando ele se interroga sobre si próprio, sobre o sentido da história. Em conseqüência da heteronomia cristã, emerge a noção que estará no centro da autonomia e da pessoa.

No entanto, o cristianismo conserva uma visão heterônima do homem, enquanto sua moral deontológica ${ }^{4}$ é definida por princípios fechados, absolutos e universais.

4 Deontologia: estudo do que deve ser, diferentemente de antologia: conhecimento do ser. 
Esta contradição encontra sua solução no ato de fé que admite que estes princípios universais e intemporais não são produzidos pelo homem, mas por Deus ele próprio falando através dos profetas e da pessoa de Cristo. Contudo, em nome da caridade e da misericórdia divina, existem, a partir do seculo XII e XIII, certas acomodações com princípios igualmente intransigentes; falo da casuística, isto é, do estudo e da resolução de casos de consciência em aparência insolúveis.

Seja como for, o cristão não é mais o joguete impotente e inconsciente de um tempo cíclico, submetido ao destino ou à natureza; em conjunto com todos os homens, ele é solidariamente responsável pela História, ou antes, por uma História, a da saúde que comporta um início (a gênese) e um fim (o retorno de Cristo). A humanidade constitui, então, em tudo o que produz esta história. É dela e dela apenas - com a graça de Deus - que depende a conclusão da Cidade de Deus, fim da história.

Desde então, tomando-se cuidado para distinguir o plano divino e o plano humano, a intervenção dos homens é não somente possível mas esperada e desejada: a reza, a devoção, a peregrinação visam a saúde da alma; os remédios, o hospital, o médico e o cirurgião cuidam do corpo.

Durante muito tempo fica justificado o provérbio presente tanto na língua árabe quanto em francês: "Eu cuidei dele(a), Deus o(a) curou".

Contudo, em pleno século XVI (1543), duas linhas sacodem esta visão: uma, a imagem do macrocosmo, a outra a do microcosmo; o sistema de Copérnico faz eco à anatomia de Vésale. O mundo fechado, ordenado, hierarquizado da cosmologia antiga, seguido pelo da teologia medieval, dá lugar ao universo infinito, onde a Terra não é mais o centro imóvel e plano, mas uma bola que gira sobre si própria em redor do sol. Contra o cosmos tradicional, é a cidade dos homens que desaparece com a queda do império romano, seguido das grandes invasões notadamente germânicas. escandinavas e árabes (séculos V-IX) e das lutas fratricidas entre os Estados saídos do império carolíngeo. Face a este "desencantamento do mundo" (Max Weber), permanece uma verdade indubitável, a que Descartes coloca luz (1641): "o cogito, ergo sum".

Desta vez, o homem é colocado na origem do conhecimento e no centro do universo mecânico em que se transformou a Natureza. Objeto da ciência, e em alguns casos, indicador de normas ou de sentido para o homem, a natureza está à mercê da razão humana que permite tornar-se "seu amo e senhor". Além disto, uma ruptura radical consumou-se: o conhecimento do que é nada diz sobre o que deve ser. Se a Natureza e Deus são mudos, resta um único referencial: a razão humana. O homem torna-se fundador de si próprio e de suas rotinas.

Com os riscos que se conhece, o homem a partir dos séculos XVII e XVIII, adquiriu sua autonomia. Freqüentemente, ele se mostra conquistador, ávido de saber, curioso de tudo, confiante em sua razão e consciente de seus poderes e de sua capacidade de produzir leis, segundo sua própria vontade. Assiste-se, então, à chegada do sujeito. Este organiza seu espaço e seu tempo. notadamente no domínio da saúde, individual e coletiva como na política. Ele se emancipou da tutela da natureza e da de Deus. Igualmente, ele utiliza a identidade separada que toda uma longa tradição tinha assinalado à cidade, ao mesmo tempo que entra em seu domínio o conhecimento das leis da Natureza e do Corpo.

Então, mobilizam-se na França no fim do século XVIII, na união do Antigo Regime e da Revolução, ligações novas e fortes entre saúde e política. Um universalis, uma emancipação está em andamento, não somente na metrópole. mas também pela via colonial pelo choque de culturas e, portanto, das coisas da saúde, nos países onde se desdobram a influência ou o poderio francês.

\section{A VACINAÇÃO ANTIVARIÓLICA}

\section{O exemplo de uma mudança de paradígma em Paris e na Algeria (século XIX)}

Situado na junção entre a saúde dada e a saúde produzida e, devido a isto, expressão de uma saúde teoricamente livre e responsável do sujeito, a vacinação antivariólica. primeira do gênero (1795), constitui "o artifício de uma infecção justamente calculada para permitir ao organismo de enfrentar a infecção selvagcm”. Em outros tempos ela pode ser lida como uma domesticação preventiva, senão da doença, ao menos de uma entre elas.

Ora. para vencer em seu projeto coletivo, ela deve resolver um certo número de dificuldades técnicas, financeiras. sociais e culturais, suscetíveis de serem analisadas e assumidas pela coletividade; igualmente, ela se inscreve no esquema previsível de uma organização hierarquizada e especializada do espaço e do tempo: a da cidade, em seguida a do Estado-Nação.

5 George Canguilhen. op. cit. p. 11. 


\section{As dificuldades técnicas}

Elas são de três ordens, uma vez suposto que as crianças vacinadas são saudáveis e capazes de reagir favoravelmente à vacinação do tipo jeneriano.

Uma questão técnica essencial será resolvida apenas nos anos 1880: a da pureza da vacina e de sua conservação, o que influi diretamente sobre a eficácia da vacina e, portanto, sobre sua imagem junto à população concernente (crianças e pais). Ora, entre 1840 e 1880 (datas aproximadas), os perigos reais ${ }^{6}$ da vacinação foram silenciados pelas autoridades políticas e medicais, tanto na França quanto na Algéria, enquanto que o problema da revacinação, conhecido após 1820, foi regulamentado em sua aplicação apenas vários de decênios após.

Devido à desconfiança. no começo do século XIX, de inúmeros médicos ainda ligados à medicina neo-hipocrática e à vista dos resultados mais ou menos válidos da vacmação jeneriana, uma segunda dificuldade aparece: o corpo médico (francês) está dividido sobre os benefícios deste método preventivo.

Uma terceira dificuldade provém da diversidade dos vacinadores: uns são médicos, oficiais de saúde ou parteiras sendo academicamente formados; os outros, professores, filantropos, charlatões ou homens de negócios que vacinam por caridade ou por solidariedade, em todo caso com convicção, enquanto que outros aí vêm um mercado lucrativo, vacinando com "manteiga fria"7.

Uma quarta dificuldade provém das lacunas do quadro médico - fora das cidades onde o pessoal médico e paramédico permanece concentrado - e da desigualdade da organização administrativa da luta antivariólica segundo as localidades e segundo os períodos.

Uma quinta dificuldade refere-se à questão crucial do financiamento da luta vacinal. Porque as autoridades políticas que fazem o regime declaram a vacinação como um bem público, esta última é, em princípio, financiada pela verba do Estado. De fato, até 1902, o Estado não torna a vacinação obrigatória, exceto para certos grupos sociais, como os escolares e os professores, ou o exército. Há, pois, incitação, educação “para a saúde"; em outros termos, face a não obrigatoriedade global imposta pela lei, a verba disponível não é suficiente, ou o é muito mal. Como conseqüência, apesar do seu sentido ético, muitos médicos só vacinam se retribuídos, tanto em Paris como no resto da França e do império colonial, donde Alger e a Algéria (conquistada a partir de 1830).

\section{As dificuldades culturais}

A técnica médica proposta, malgrado uma organização hierarquizada e, em parte, profissionalizada do espaço da cidade na metrópole e na colônia que era a Algéria, confronta-se, principalmente, com uma visão global distinta e antiga, portanto bem anexada ao espírito das pessoas. Afrontamentos aparecem em quatro domínios: das representações da doença e, mais genericamente, do corpo; das representações das regras da Natureza, seja animal ou humana; da representação do outro, especificamente na Algéria, nos árabes e nos kabyles; das representações do tempo que obstaculiza a idéia de antecipação, a de prevenção e, aqui, de medicina preventiva.

\section{a) As representações da doença e do corpo}

Tanto na região muçulmana (Algéria) quanto na região cristã (França), havia anteriormente a idéia de que a varíola é uma doença salutar, ou mesmo enviada por Deus, e que é normal, que é bom ter uma, em particular, porque ela faz evacuar os humores nocivos do corpo por intermédio do pus e das pústulas.

\section{b) As representações dos reinas da natureza}

Um médico, no tempo do império napoleônico, escreveu em 1802: "não se pode determinar a comunicar a suas crianças um mal que deve sua origem a um animal; teme-se as conseqüências da mistura dos humores de um animal e o de um homem”. O temor de uma “bowinisação” da descendência, ao menos na França, existe de modo claro e seguro.

\section{c) As representações do Outro (Algéria)}

Na Algéria, as populações autóctones viam com desconfiança médicos militares, cristãos e pois infieis, quererem introduzir uma técnica gratuita. Efetivamente, ela provinha do invasor e, ao mesmo tempo, ela se opunha à tradicional variolização efetuada desde há muito tempo pelos “ta’bib” (médicos tradicionais).

Evidentemente, este tipo de reação não existia na França, ao menos nas elites urbanas. Entretanto, uma mesma desconfiança era suscitada na França e na Algéria pela gratuidade desta prática. O cidadão, o operário, o camponês, na França e na Algéria, temiam que o Estado mar-

6 Transmissão de dermatoses e da sífilis vacinal.

7 Discurso do prefeito de Saint-Wendel (03/05/1809). 
casse assim as crianças para elevar o imposto ou para enviar os meninos ao serviço militar. Especificamente na Algéria, estava o temor de que a vacinação tornava estéril.

\section{d) As representações do tempo}

Na França como na Algéria, médicos e administradores - civis ou militares - sublinhavam que as pessoas vivessem na urgência do presente, sem se preocupar com o futuro; elas estavam apenas preocupadas com sua saúde quando a sentiam imediatamente ameaçada. Nestas condições, os conceitos de futuro e de prevenção tiveram muita dificuldade para se impor.

\section{Os sucessos tardios e desiguais da vacinacão}

Tais sucessos se explicam por razões de ordem técnica, financeira e cultural que viemos de evocar. Devido a uma presença afinada do corpo médico na cidade, a uma organização administrativa e sanitária poderosa, com taxas de alfabetização mais elevadas, as cidades da França, sobretudo as povoadas por europeus na Algéria, mas também na Alemanha e em Quebec, tiveram uma cobertura vacinal mais elevada que no resto do país.
Uma exceção foi a cidade de Paris, o que pode ser explicado por Paris contar com muitos migrantes de origem camponesa e também por ser as pessoas que iam ao domicílio do médico, ao hospital ou à prefeitura para serem vacinadas, enquanto que no resto da França e na Algéria, eram os vacinadores que se deslocavam ao domicílio das pessoas, a porcentagem de europeus vacinados sendo de 4 a 12 vezes superior à dos autóctones (muçulmanos e ismaelitas), segundo as cidades.

\section{CONCLUSÃO}

Culturalmente falando, a adoção de uma técnica preventiva exige, pois, que os espíritos mudem e que os comportamentos evoluam. A organização do tempo, do espaço e dos "grupos líderes", símbolo da modernidade, apoia-se seja na medicina, sobre a escola, sobre a imprensa, para fazer adotar, pouco a pouco, uma revolução mental, saída da cidade, que colocava diferentemente, de modo laicizado em particular, a questão das relações do corpo com a doença, com o tempo, com o espaço e com o dinheiro, em outros termos, a questão da saúde. 